\title{
Risk factors in skin infections - a pilot study
}

\author{
Hafsteinn Oli Gudnason², Mar Kristjansson ${ }^{1,3}$, Heida Björg Gunnlaugsdottir ${ }^{1}$, Jon Magnus Kristjansson 1,2* \\ From Danish Society for Emergency Medicine: Research Symposium 2010 \\ Roskilde, Denmark. 20-21 May 2010
}

\section{Background}

The object of this prospective pilot-study was to outline the patient-group that presents to the emergency department at Landspitali university hospital, Reykjavik, Iceland for suspected cellulitis. Our main focus was on demographic characteristics, IV vs. oral antibiotic treatment and inpatient vs. outpatient treatment.

\section{Methods}

We included patients presenting to our emergency department from mid February to mid April 2010, were over 18 years, had physical and mental capacity to answer the questions related to the study and had suspected cellulitis. We documented demographic information on each patient, the length of stay at the emergency department, whether the patient was admitted or sent discharged, what antibiotics were used and whether it was given intravenously or orally.

\section{Results}

31 patients were included in the study, 22 men and 9 women. The average age was 53 years. The mean BMI (body mass index) was 29.7. 74\% were overweight (BMI $>25$ ) and $40 \%$ were obese (BMI > 30). The most common location was lower extremity $(66 \%)$ followed by upper extremity (16\%). Nine patients $(29 \%)$ were admitted after initial evaluation, eleven patients (35.5\%) were kept at a clinical decision unit within the department for up to 24 hours for re-evaluation and iv. antibiotic treatment. Of those, five were eventually admitted and six were discharged. Eleven patients (35.5\%) were discharged directly after initial evaluation. Of all patients, 77\% received intravenous antibiotic treatments while $23 \%$ received oral antibiotics.

\footnotetext{
* Correspondence: jonmkr@lsh.is

'University of Iceland, Dept. of Medcine, Iceland

Full list of author information is available at the end of the article
}

\section{Conclusion}

Our study suggests that overweight and middle aged people are at higher risk of acquiring skin infection and that the most frequent location is the lower extremity which is in agreement with other studies. The male/ female ratio should be even or lower according to other studies.

In our study $45 \%$ of the patients were eventually admitted. In about half of the cases where the need for admission was unclear at presentation, and the patients were kept overnight for observation and IV antibiotics in a clinical observation unit the admission was aborted. We believe that this practice is highly cost-effective as it decreased the number of admissions by around $25 \%$.

\section{Author details \\ 'University of Iceland, Dept. of Medcine, Iceland. 'Emergency Dept., Landspitali University Hospital, Iceland. ${ }^{3}$ Dept. of Infectious Diseases, Landspitali University Hospital, Iceland.}

Published: 17 September 2010

doi:10.1186/1757-7241-18-S1-P28

Cite this article as: Gudnason et al: Risk factors in skin infections - a pilot study. Scandinavian Journal of Trauma, Resuscitation and Emergency Medicine 2010 18(Suppl 1):P28.

Submit your next manuscript to BioMed Central and take full advantage of:

- Convenient online submission

- Thorough peer review

- No space constraints or color figure charges

- Immediate publication on acceptance

- Inclusion in PubMed, CAS, Scopus and Google Scholar

- Research which is freely available for redistribution

Submit your manuscript at www.biomedcentral.com/submit
C Biomed Central 